\title{
Reflections on PTSD's future in DSM-V
}

\author{
Gerald M. Rosen, Scott O. Lilienfeld, B. Christopher Frueh, Paul R. McHugh \\ and Robert L. Spitzer
}

\section{Summary}

Research findings have fuelled debate on the construct validity of post-traumatic stress disorder (PTSD).

Accompanying these issues are competing suggestions to redefine PTSD's criteria, including a recent proposal by DSM-V committee members. We review various approaches to revising the PTSD diagnosis and conclude that proposed changes should be placed in the appendix that the DSM has used for experimental criteria sets.

\section{Declaration of interest}

None.
Gerald M. Rosen (pictured) is a Clinical Professor with the University of Washington's Department of Psychology, and with the Medical School's Department of Psychiatry and Behavioral Sciences. Scott O. Lilienfeld is Professor of Psychology at Emory University, Atlanta, Georgia, past President of the Socity for a Science of Clinical Psychology, and current Editor-in-Chief of the Scientific Review of Mental Health Practice. B. Christopher Frueh is a Professor of Psychology at the University of Hawaii, Hilo, Hawaii, and MCNair Scholar and Director of Clinical Research at the Menninger Clinic, Houston, Texas. Paul R. McHugh is a University Distinguished Service Professor of Psychiatry at Johns Hopkins School of Medicine, Baltimore, Maryland, having been Psychiatrist-in-Chief at Johns Hopkins Hospital, 1975-2001. Robert L. Spitzer is Professor of Psychiatry in the Department of Psychiatry at Columbia University, New York. He led the development of the third edition of the American Psychiatric Association's Diagnostic and Statistical Manual (DSM-III) and its revision (DSM-III-R).

Three decades of research on post-traumatic stress disorder (PTSD) has informed our understanding of post-traumatic psychiatric morbidity. At the same time, the very research spurred by PTSD's introduction in DSM-III has come to challenge almost every aspect of the construct's originating assumptions. ${ }^{1,2}$

\section{PTSD and DSM-V}

The current state of affairs surrounding PTSD is reflected in conflicting proposals for how the syndrome should be operationalised in the forthcoming and fifth edition of the DSM (DSM-V), due for publication in 2013. Proposals for how to distinguish traumatic events (Criterion A) from more ordinary stressors have included encouragements to better adhere to current definitions, ${ }^{3}$ modifications to current wording, ${ }^{4-8}$ and the radical suggestion that Criterion A should be eliminated entirely. ${ }^{9}$ In a recent posting on the internet, members of the DSM-V workgroup on PTSD proposed the approach of modifying earlier definitions. In their proposed draft criteria, now available for public comment, the subjective component of a traumatic event (Criterion A2), first introduced in DSM-IV, ${ }^{10}$ is eliminated altogether, whereas objective aspects of life-threatening trauma are reinforced. We applaud these suggestions because they may reduce the problem of 'criterion creep' that has been associated with recent DSM operationalisations of PTSD. ${ }^{11}$

Still, the committee's proposal for Criterion A does not resolve or even address serious problems with PTSD's underlying assumption of a distinctive and specific etiology. ${ }^{1}$ It also is telling that committee members perceived the need to specify that watching television or films should not qualify as a traumatic event. This rather remarkable qualification represents a milestone in the history of psychiatry: heretofore it was not thought necessary to specify that post-traumatic psychiatric disorder did not result from exposure to media (e.g. television shows) that individuals freely choose to watch. That such a statement was believed necessary is further testament to the 'Criterion A problem.'

In the absence of a coherent position on the question of specific etiology - a position that the DSM-V proposal does not address directly or indirectly - the validity of PTSD largely rests on the distinctiveness of its clinical syndrome. Yet PTSD's symptom criteria (Criteria B-D) remain as controversial as Criterion A, largely because of substantial overlap with other disorders (e.g. specific phobia, depression, dissociative disorders). ${ }^{2}$ To address this concern, some have proposed the elimination of non-distinctive symptoms. ${ }^{7}$ At the same time, the question regarding which of PTSD's symptoms best identifies the syndrome remains unclear. There has been the suggestion that re-experiencing symptoms (Cluster B: e.g. nightmares) are central because they involve content related to the traumatic event. ${ }^{5}$ Others have found that re-experiencing symptoms are non-specific stress responses associated with multiple disorders. ${ }^{1}$ Further, North et al proposed that the hallmark symptoms of post-traumatic morbidity involve avoidance and emotional numbing (Cluster C). ${ }^{6}$ A more sweeping alternative suggests that PTSD often results from emotions such as anger, guilt and shame, and therefore is not primarily a fear- or anxiety-based condition. ${ }^{12}$ This viewpoint argues for an entirely new classification category that encompasses a spectrum of traumatic stress disorders, one of which would be PTSD. Most recently, committee members for the DSM-V provided a listing of 21 possible symptoms and signs, grouped into four (rather than the current three) clusters (intrusion symptoms, avoidance, negative affect, hyperarousal) ${ }^{8}$

It is instructive to recall that the PTSD clinical syndrome was first operationalised in DSM-III ${ }^{13}$ by only 12 symptoms, grouped into three clusters. This arrangement yielded 135 combinations by which an individual could meet the minimum requisite symptom criteria. In DSM-IV, ${ }^{10} 17$ symptoms were grouped in the same three clusters, with minimum criteria yielding 1750 combinations. The current proposal for DSM-V, in which 21 symptoms are grouped into four clusters, allows for 10500 ways to meet minimum requisite criteria! This expansion is beyond anything experienced for other diagnoses. Minimum criteria for diagnosing major depressive episodes, for example, allowed for 70 combinations in DSM-III, 112 combinations in DSM-IV, and essentially no new combinations in DSM-V. Minimum criteria for diagnosing generalised anxiety disorder allowed for 4 combinations in DSM-III, 20 combinations in DSM-IV, and a proposed reduction to 8 combinations in DSM-V. Once again, PTSD is sui generis in the DSM with regard to the expansion of its diagnostic criteria and continued blurry boundaries. ${ }^{7}$ By 
vastly increasing permitted heterogeneity at the phenotypic level, DSM-V risks increasing etiological heterogeneity, while providing no resolution to the symptom overlap conundrum.

\section{A sound scientific alternative}

Continuing controversy over how to operationalise PTSD in $\mathrm{DSM}-\mathrm{V}$ has led to the suggestion that the diagnosis might best be relegated to the manual's appendix for experimental criteria sets. ${ }^{1}$ A concern that such a move would lead to the construct's demise is not warranted, as illustrated by strong interest in Spitzer's proposal for binge eating disorder despite its placement in the appendix of DSM-IV. Yet another approach that makes use of the DSM's appendix for experimental criteria sets is illustrated by the diagnosis of dysthymic disorder. With that diagnosis, an alternative criterion set was listed in the appendix for experimental sets, while extant criteria for dysthymic disorder remained in the main text of DSM-IV.

We believe that use of the DSM's appendix for experimental criteria sets can operationalise PTSD in a manner that encourages research and allows for treatment of a wide range of post-traumatic reactions, while delaying scientifically premature acceptance of any specific proposal. This approach can also serve to remind clinicians that PTSD in its present form should not be reified to the status of a distinct disorder in nature, at least until such time that we better understand the full range of normal and disordered reactions that occur after traumatic and other high-magnitude stressors. ${ }^{7,14,15}$

Gerald M. Rosen, PhD, University of Washington, Seattle, Washington; Scott O. Lilienfeld, PhD, Emory University, Atlanta, Georgia; B. Christopher Frueh, PhD, University of Hawaii, Hilo, Hawaii; Paul R. McHugh, MD, Johns Hopkins University School of Medicine, Baltimore, Maryland; Robert L. Spitzer, MD, Columbia University, New York, USA

Correspondence: Gerald M. Rosen, Department of Psychology and Psychiatry, University of Washington, 117 East Louisa Street, PMB-229, Seattle, WA, USA. Email: grosen@u.washington.edu

First received 10 Mar 2010, accepted 23 Mar 2010

\section{References}

1 Rosen GM, Lilienfeld SO. Posttraumatic stress disorder: an empirical analysis of core assumptions. Clin Psychol Rev 2008; 28: 837-68.

2 Rosen GM, Spitzer RL, McHugh PR. Problems with the post-traumatic stress disorder diagnosis and its future in DSM-V. Br J Psychiatry 2008; 192 : 3-4.

3 Weathers FW, Keane TM. The criterion A problem revisited: controversies and challenges in defining and measuring psychological trauma. J Trauma Stress 2007; 20: 107-21.

4 Kilpatrick DG, Resnick HS, Acierno R. Should PTSD Criterion A be retained? J Trauma Stress 2009; 22: 374-83.

5 McNally RJ. Can we fix PTSD in DSM-V? Depress Anxiety 2009; 26 : 597-600.

6 North CS, Suris AM, Davis M, Smith RP. Toward validation of the diagnosis of posttraumatic stress disorder. Am J Psychiatry 2009; 166: 34-41.

7 Spitzer RL, First MB, Wakefield JC. Saving PTSD from itself in DSM-V. J Anxiety Disord 2007; 21: 233-41.

8 American Psychiatric Association. 309.81: Posttraumatic Stress Disorder APA, February 2010 (http://www.dsm5.org/ProposedRevisions/Pages/ proposedrevision .aspx? rid=165)

9 Brewin CR, Lanius RA, Novac A, Schnyder U, Galea S. Reformulating PTSD for DSM-V: life after Criterion A. J Trauma Stress 2009; 22: 366-73.

10 American Psychiatric Association. Diagnostic and Statistical Manual of Mental Disorders (4th edn) (DSM-IV). APA, 1994.

11 Rosen GM. Traumatic events, criterion creep, and the creation of pretraumatic stress disorder. Sci Rev Ment Health Pract 2004; 3: 46-7.

12 Resick PA, Miller MW. Posttraumatic stress disorder: anxiety or traumatic stress disorder? J Trauma Stress 2009; 22: 384-90.

13 American Psychiatric Association. Diagnostic and Statistical Manual of Mental Disorders (3rd edn) (DSM-III). APA, 1980.

14 Bryant RA. Treating the full range of posttraumatic reactions. In Clinician's Guide to Posttraumatic Stress Disorder (eds GM Rosen, BC Frueh): 205-34. John Wiley, 2010.

15 McHugh PR. Try to Remember: Psychiatry's Clash over Meaning, Memory, and Mind. Dana Press, 2008. 